\title{
PERAN MAQASID SYARIAH DALAM MEMELIHARA KEDUDUKAN AGAMA ISLAM DI MALAYSIA
}

\author{
Ayu Nor Azilah Mohamad \\ Kolej Universiti Islam Antarabangsa Selangor, Malaysia, ayunorazilah@kuis.edu.my
}

Mohamed Ali Haniffa

Universiti Utara Malaysia, Malaysia, m.ali@uum.edu.my

Wayu Nor Asikin Mohamad

Kolej Universiti Bestari, Terengganu, Malaysia,wayu@ucbestari.edu.my

Diterima: 20 Februari $2018 \quad$ Direvisi : 14 Maret 2018 Diterbitkan: 30 Juni 2018

\begin{abstract}
This article discusses Maqasid Shariah upholding the position of Islam as the official religion of Malaysia as enshrined in the Federal Constitution. However, other religions are allowed to be practiced freely for as long as it does not interfere with public order. The upholding of Islam is as stated in Article 3 (1) of the Federal Constitution of Malaysia through the Malay Rulers at state level and the Yang di-Pertuan Agong at the Federal level, the establishment of the Islamic Religious Council in each state and also the responsibility of the National Council of Religious Affairs. This is because Islam is the religion of Allah S.W.T. and it is the greatest gift to save and protect people from catastrophes. This study uses secondary sources and library research methods. The findings show that the position of Islam in Malaysia is upheld through the implementation of Maqasid Shariah. This is in line with the current situation of plural society in Malaysia where everyone is given freedom to practice their religion and culture.
\end{abstract}

Keywords: Religion, Islam, Maqasid, Syariah

\begin{abstract}
Abstrak
Artikel ini membincangkan tentang Maqasid Syariah memelihara kedudukan agama Islam di Malaysia. Islam diiktiraf dalam Perlembagaan Persekutuan Malaysia sebagai agama rasmi persekutuan. Akan tetapi agama-agama lain juga boleh diamalkan secara bebas selagi tidak mengganggu ketenteraman awam. Pemeliharaan kedudukan agama Islam dilaksanakan melalui Perkara 3 (1) Perlembagaan Persekutuan Malaysia melalui peranan Raja-raja Melayu pada peringkat negeri dan Yang di-Pertuan Agong di peringkat Persekutuan, penububan Majlis Agama Islam di setiap negeri dan termasuk tanggungjawab Majlis Kebangsaan Hal Ehwal Agama Islam . Hal ini kerana agama Islam ialah agama Allah S.W.T. dan merupakan nikmat yang paling besar untuk. menyelamatkan serta melindungi manusia daripada segala bencana. Kajian ini menggunakan sumber sekunder dan kaedah penyelidikan kepustakaan. Hasil kajian mendapati bahawa kedudukan agama Islam di Malaysia terpelibara melalui pelaksanaan Maqasid Syariah. Perkara ini sangat bersesuaian dengan lanskap masyarakat majmuk di Malaysia yang diberi kebebasan untuk mengamalkan agama, budaya dan adat resam masing-masing.
\end{abstract}

Kata kunci: Agama, Islam, Maqasid, Syariah

\section{PENDAHULUAN}

Malaysia adalah sebuah negara yang mempunyai banyak agama. Rakyat mengamalkan agama-agama yang berlainan seperti agama Islam, Hindu, Buddha, Kristian dan kepercayaan lain. Orang Melayu hanya menganut satu agama iaitu Islam. Sesuatu yang asing sekiranya seorang bangsa Melayu itu bukan beragama Islam. Seseorang seumpama itu dianggap 'murtad' iaitu terkeluar daripada agama. Malah untuk menjadi seorang Melayu, seseorang itu mestilah beragama Islam meskipun mungkin tidak mengamalkan ajaran Islam sepenuhnya atau pun menjadi penganut Islam yang taat. Mengaitkan agama secara sepenuhnya dengan bangsa adalah asas kepada 
pemikiran orang Melayu. Sehinggakan agama Islam telah menjadi suatu unsur yang penting untuk mendefinisikan Melayu mengikut undang-undang dan Perlembagaan. Perkara 160 Perlembagaan Persekutuan Malaysia mentakrifkan seorang 'Melayu' itu seharusnya seorang yang beragama Islam, lazimnya bercakap bahasa Melayu dan menurut adat istiadat Melayu. .

Kedudukan agama Islam terpelihara melalui jaminan yang termaktub dalam Perlembagaan Persekutuan Malaysia. Perkara 3 telah dituliskan sedemikian: "Islam adalah agama Persekutuan tetapi agama-agama lain boleh juga diamalkan dalam aman dan damai di mana-mana bahagian dalam Persekutuan". 2 Walaupun agama Islam dijadikan agama bagi Persekutuan, tetapi kedudukan agama Islam masih lagi menjadi tanggungjawab kerajaan negeri yang diketuai oleh raja atau sultan. Selain itu, penubuhan Majlis Agama Islam setiap negeri juga bertujuan untuk memelihara kedudukan agama Islam. Hal yang demikian ini, akan dibincangkan dengan lebih lanjut dalam huraian di bawah.

\section{AGAMA ISLAM}

Islam ialah agama yang dianuti oleh majoriti rakyat di Malaysia. Seseorang yang beragama Islam bermaksud menyerah diri dan mengikuti perintah Allah SWT serta menjadikan Nabi Muhammad SAW sebagai contoh terbaik. Penganut Islam harus memberi kesaksian bahawa tiada Tuhan melainkan Allah SW'T dan Nabi Muhammad SAW adalah utusan-Nya. Sumber utama ajaran Islam ialah Alquran dan keseluruhan teksnya tidak boleh diubah. Sumber yang kedua ialah al-Sunnah yang merangkumi ucapan, tindakan dan sifat-sifat Rasulullah SAW dalam bentuk menifestasi ajaran Islam yang dikenali sebagai hadis. Penganut agama Islam wajib percaya kepada Allah SW'T, semua rasul, kitab suci yang telah

1 (Tun Mohd Salleh Abas, 2006: 45)

2 (Tun Mohd Salleh Abas, 2006: 320) diturunkan oleh Allah SWT, malaikat, hari kiamat dan qada serta qadar. Dalam hadis juga terkandung Sirah yang mempunyai sejarah hidup Baginda. Malah, hadis berperanan sebagai pelengkap kepada Alquran dan juga sumber inspirasi umat Islam bagi membentuk, membangun dan mengembangkan tamadun. ${ }^{3}$

Sumber ajaran Islam ketiga ialah ijtihad, ijmak, qiyas, syura dan sebagainya. Untuk itu, para ulama dan cendekiawan Islam melakukan usaha dalam mengolah hukum terhadap perkara-perkara baharu berdasarkan keilmuan yang dimiliki dengan merujuk kepada sumber Alquran dan Sunnah. Islam ialah suatu peraturan kehidupan dan agama praktikal berkaitan dengan kehidupan dunia serta akhirat. Dalam Islam, Allah S.W.T. telah menentukan jalan yang perlu dilalui sebagai panduan kepada manusia dalam bentuk syariah. Syariah ialah prinsip Islam tertinggi dengan mengatur kehidupan harian dalam kesemua aspek kehidupan daripada urusan ibadat sehinggalah urusan ekonomi, pemerintahan dan kemasyarakatan. ${ }^{4}$

Islam membuka ruang kepada kesatuan seluruh bangsa. Setiap manusia tanpa mengira bangsa dan keturunan adalah setaraf di sisi Tuhan. Prinsip-prinsip keadilan harus ditegakkan dan dilaksanakan merentasi perbezaan agama. Tiada perbezaan taraf kecuali ketakwaan dan kebersihan hati. Hal ini menjadi satu landasan yang baik untuk mengharungi kehidupan yang harmoni dan berupaya menghapuskan perasaan kesukuan serta perkauman kemasyarakatan (Shamsul Amri Baharuddin, 2016: 154). Islam ialah agama sejagat yang berada dalam kelasnya tersendiri dari segi kosmologi, epistemologi, metafizik dan weltanschaunng. Islam juga mengiktiraf kewujudan pelbagai bangsa, budaya dan cara hidup yang berbeza-beza:

3 (Osman Bakar et.al. 2017: 39)

4 (Shamsul Amri Baharuddin, 2016: 153) 
“... kami jadikan kamu berbangsa-bangsa dan berpuak-puak supaya kamu dapat berkenalkenalan antara satu sama lain" (al-Hujutaat: 13) Sejarah juga menjelaskan dengan penubuhan kerajaan Islam di Madinah (622M) telah menandakan pengiktirafan Islam terhadap hak dan tanggungjawab orang bukan Islam dalam sebuah negara Islam. Sementara itu, dalam kontrak sosial antara etnik Melayu, Cina dan India yang bergabung dalam satu parti Perikatan turut mencapai kata sepakat dalam beberapa perkara. Antaranya ialah berkaitan dengan agama Islam. Selepas parti Malayan Chinese Association (MCA) dan Malayan Indian Congress (MIC) menyedari pengorbanan yang dibuat oleh orang Melayu iaitu dengan melonggarkan syarat kerakyatan berasaskan jus soli yang ditentang selama ini. Oleh itu, kaum Cina dan India menerima hakikat sejarah negara Malaysia dan bersedia secara sukarela, menerima dan mengakui hak keistimewaan orang Melayu semenjak turun temurun. Mereka juga turut mengakui agama Islam sebagai agama rasmi negara Malaysia. ${ }^{5}$

Antara ciri-ciri utama agama Islam ialah:

Ajaran yang Menyeluruh (sempurna). Islam merangkumi seluruh aspek kehidupan manusia termasuk undang-undang (syariah), akidah, akhlak, hubungan dengan Allah SWT dan hubungan sesama manusia. Islam juga mementingkan dan menyeru keadilan untuk semua insan, sama ada Islam atau bukan Islam, kawan atau lawan dan sama ada mempunyai hubungan keluarga atau sebaliknya. ${ }^{6}$

Aspek ekonomi. Ajaran Islam memberi kebebasan kepada umatnya untuk berusaha mencari kekayaan dengan cara yang mulia dan bersih. Malah Islam pertanggungjawabkan membasmi kemiskinan dan penderitaan masyarakat di tangan orang yang mempunyai harta banyak serta memiliki kuasa. Islam menentang sistem ekonomi yang mempunyai

5 (Abd. Manaf Haji Ahmad, 2009: viii)

${ }^{6}$ (Ab. Aziz Mohd Zin et.al, 2014: 54) unsur eksploitasi, penindasan, pemerasan, monopoli dan penipuan. Islam turut mewajibkan zakat kepada golongan yang berharta dan menggalakkan umat Islam menderma serta berkorban untuk kebajikan orang lain. Ini merupakan salah satu cara pembersihan harta dan hati. Malah satu mekanisme dalam usaha membanteras kemiskinan.

Aspek politik. Islam mendidik agar setiap orang menghormati hak asasi setiap manusia. Oleh itu, Islam mengutamakan konsep musyawarah, keadilan dan pemilihan pemimpin secara adil tanpa membezakan manusia berdasarkan kelas, keturunan, bangsa, agama atau pun warna kulit.

Aspek sosial. Islam mementingkan kehormatan diri manusia. Tidak wujud perhambaan dan pemujaan melainkan kepada Allah SWT semata-mata. Selain itu, Islam juga mendidik agar umat manusia menjaga kebersihan diri. Seluruh manusia dilahirkan dalam keadaan bersih dan suci. Manusia bertanggungjawab terhadap setiap tindaktanduk yang dilakukan dan tidak akan menanggung dosa orang lain.

Pendapatan halal dan suci. Islam melihat semua pekerjaan suci asalkan halal walaupun berstatus rendah. Pendapatan yang diperoleh haruslah secara halal dan suci untuk menjaga keberkatan. Islam mengajar majikan agar berlaku adil dengan tidak melakukan pemerasan terhadap pekerja. Manakala pekerja pula dituntut supaya amanah kepada majikan.

Aspek keluarga. Islam mengajar supaya menghormati kedua-dua ibu bapa dengan memberi kasih sayang yang sama kepada anakanak, berlaku adil kepada isteri dan membina hubungan yang baik dengan kaum keluarga serta jiran tetangga.

Prinsip kebebasan beragama. Walaupun agama Islam menjadi agama rasmi bagi Persekutuan, agama-agama lain boleh juga diamalkan dalam keadaan aman dan damai di mana-mana bahagian dalam Persekutuan ini. 
Setiap orang berhak mengamalkan dan mengembangkan agamanya tetapi pengembangan agama kepada orang-orang Islam boleh dikawal serta disekat oleh undangundang negeri. Setiap kumpulan agama dengan tidak mengecualikan mana-mana agama adalah berhak mentadbir hal ehwal agamanya sendiri. Juga turut dibenarkan untuk menubuhkan dan menyelenggarakan yayasan untuk maksud agama serta kebajikan. Malah juga berhak untuk mengajarkan agama kepada anak-anak sendiri, berhak memperoleh dan memegang hartanya sendiri untuk agamanya. ${ }^{7}$

\section{MAQASHID SYARIAH}

Manifestasi pelaksanaan syariah dalam tamadun Islam adalah untuk mengatur kehidupan manusia atas asas makruf dan mengelak kemungkaran. Makruf bermaksud segala nilai luhur dan sifat baik yang biasanya diterima oleh naluri manusia sebagai baik. Manakala mungkar pula membawa makna segala macam dosa dan kejahatan yang selalunya dikecam oleh naluri manusia sebagai jahat. Prinsipnya ialah syariah bertujuan untuk menyelamatkan dan memelihara lima perkara yang menjadi asas kepada kehidupan manusia. Lima perkara tersebut ialah:

\section{Memelihara Agama.}

Agama Islam menjadi teras kepada tamadun Islam. Oleh itu, menjadi tanggungjawab penganutnya untuk mempertahankan agama Islam. Islam ialah agama Allah SWT dan merupakan nikmat yang paling besar bagi menyelamatkan manusia daripada segala bencana. Kedudukan istimewa Islam sebagai agama di sisi Allah SWT telah dinyatakan dalam surah al-Ma'idah (5:3) yang bermaksud:

"Hari ini Aku telah sempurnakan bagi kamu agama kamu, dan Aku telah cukupkan nikmatKu kepada kamu, dan Aku telah redakan Islam itu menjadi agama untuke kamu."

${ }^{7}$ (Tun Mohd Salleh Abad, 2006: 321)
Apabila seseorang itu telah memilih Islam, maka wajib ke atas mereka untuk menunaikan tanggungjawab sebagai muslim. Jika sekiranya keluar daripada Islam akan dianggap murtad. Bagi menjamin supaya iman dan agama ini terpelihara, Islam telah memperuntukkan undang-undang serta bentuk hukuman yang sepatutnya bagi orang yang keluar daripada agama Islam atau golongan murtad. ${ }^{8}$

\section{Memelihara Nyawa.}

Dalam Islam, Allah SWT dikatakan Tuhan Maha Hidup dan Maha Berkuasa. Justeru, Allah SWT mengurniakan hak hidup kepada sekalian makhluk termasuk manusia. Hak ini diberikan dan tiada sesiapa pun boleh mengambilnya kecuali Allah SWT. Alquran menjelaskan yang maksudnya:

"Dan sesungguhnya Kami-lah yang menghidupkan dan mematikan." (Surah al-Hijr, 15:23).

Hak hidup tidak dibenarkan untuk diambil tanpa kebenaran dan keizinan Allah SWT. Alquran menyebutkan:

"Siapa yang membunuh orang tanpa kesalahan atau berbuat kerosakan di bumi, maka seolaholah dia membunub manusia semuanya." (Surat al-Ma'idah, 5:32)

Untuk itu, manusia dilarang membunuh tanpa hak. Sesiapa yang melanggar peruntukan undang-undang syarak ini dianggap melakukan jenayah dan berdosa besar. Islam juga melarang penganutnya membunuh diri. Hal ini kerana perbuatan ini menentang dan melawan ketetapan serta kekuasaan Allah SWT. Pembalasan kepada perbuatan akan mengakibat seseorang itu berhak memperoleh azab yang berat di akhirat nanti (Ahmad Zaki et al. 2015: 32). Alquran menyebutkan:

"Siapa yang melakukan demikian secara ceroboh dan zalim, maka Kami (Allah) akan membakarnya dengan api." (Surat al-Nisa, 4:30).

8 (Osman Bakar et.al. 2017:46) 
Memelihara Akal.

Dalam Islam, akal menduduki tempat ketiga selepas Alquran dan al-Hadis. Ini merupakan hujah batin yang Allah SWT anugerahkan kepada manusia. Akal berperanan penting dalam kehidupan manusia. Akal juga yang membezakan antara manusia dengan haiwan malah akal dapat menentukan sama ada manusia itu layak untuk diberi tanggungjawab atau tidak. Islam telah menetapkan beberapa langkah untuk memelihara akal, di antaranya adalah dengan mewajibkan setiap individu muslim menuntut ilmu pengetahuan tanpa batasan masa, tempat dan bangsa. Buktinya Nabi Muhammad SAW bersabda: "Tuntutlab ilmu dari buaian binggan ke liang lahad" (HR. Muslim)

Dengan menggunakan akal, manusia boleh menentukan sama ada sesuatu itu baik atau buruk, berkualiti atau pun rosak dan dengan akal juga membolehkan manusia terus maju serta berkembang. Islam menggalakkan pemikiran mengenai ketakwaan dan ketauhidan kepada Allah SWT, yang terbuka serta bersih daripada segala unsur keburukan, kepalsuan, khayalan, keraguan dan was-was. Islam sangat mementingkan pemeliharaan akal dan melarang manusia melibatkan diri dengan perkara-perkara yang boleh menghilangkan fungsi akal. Justeru itu, Islam melarang penganutnya memakan dan minum sesuatu yang dilarang oleh Allah SWT. ${ }^{9}$ Contohnya mengambil minuman keras dan dadah. Sekiranya manusia hilang fungsi akal akan menyebabkan kerosakan kepada diri, keluarga, masyarakat dan tamadun. Firman Allah S.W.T. dalam surah al-Maidah (5:90) yang bermaksud:

"Wabai orang yang beriman, bahawa sesunggubnya arak, judi, pemujaan berhala dan tenung nasib adalab semuanya keji daripada perbuatan syaitan. Oleh itu, bendaklah kamu menjaubi supaya kamu berjaya."

\section{Memelihara Kehormatan dan Keturunan.}

\footnotetext{
${ }^{9}$ (Ad Aziz Mohd Zin et.al, 2014: 57)
}

Manusia dicipta oleh Allah SWT dengan sebaik-baik kejadian. Setiap manusia diberikan hak untuk memelihara kehormatan diri dan tiada seorang pun boleh melucutkan hak kehormatan tersebut kecuali dengan keizinan Allah SWT. Maruah diri dan memelihara kehormatan keturunan boleh dikawal melalui sistem perkahwinan untuk menjamin keturunan manusia agar tidak tergugat. Nabi Muhammad SAW telah menerangkan bahawa seluruh umat manusia adalah berasal daripada satu bapa dan satu ibu menerusi sabda Baginda SAW yang bermaksud: "Wahai manusia, sesungguhnya Tuhan kamu satu (tunggal) dan kamu sekalian berasal daripada Adam dan Adam berasal daripada tanah." (HR. alBukhari dan Muslim)

Islam melarang manusia melakukan perkara-perkara negatif seperti berzina, seks bebas dan hubungan luar tabii. Perbuatan negatif ini boleh memudaratkan institusi kekeluargaan dan meruntuhkan keturunan manusia. Allah SWT telah berfirman dalam surah al-Isra' (17:32) yang bermaksud:

"Dan janganlah kamu menghampiri zina, sesunggubnya zina itu adalah suatu perbuatan yang keji dan jalan yang membawa kerosakan."

\section{Menjaga Harta Benda.}

Islam telah menetap dan memberi garis panduan mengenai hak untuk memiliki harta benda dan kewajipan untuk mempertahankannya. Malah dengan kemudahan melalui kaedah ilmu faraid pula menjadi jalan untuk menafkahkan harta tersebut secara halal mengikut fitrah manusia sendiri. Setiap manusia dihehendaki berusaha mencari harta dalam kehidupannya mengikut kemampuan dan kebolehan masing-masing. Allah SWT meluaskan bidang pemilikan harta benda seluas-luasnya kepada makhluk-Nya di dunia tanpa sekatan. Sesiapa yang mengambil harta orang lain tanpa kebenaran seperti mencuri dan menyamun akan dikenakan hukuman berat (Ab. Aziz Mohd Zin, 2014: 
58). Oleh yang demikian, Islam telah mengatur aktiviti-aktiviti ekonomi berlandaskan kepada syariat di bawah konsep muamalah. Firman Allah SWT dalam surah al-Baqarab (2:188) yang bermaksud:

"Dan janganlah kamu mengambil harta orang lain dengan jalan yang salah, dan janganlah kamu memberi rasuab kepada bakim-bakim kerana bendak mengambil sebahagian daripada harta manusia dengan berbuat dosa, pada hal kamu mengetahui salahnya."

Syariah merangkumi segala perintah Allah SWT dalam bentuk hukum dan peraturan yang bersifat menyeluruh dan bidang yang sangat luas. Ini termasuk juga seluruh perintah dan ketentuan Allah SWT yang diwahyukan sama ada yang ditegaskan dalam Alquran serta berasaskan Sunnah. Di dalamnya terdapat pelbagai aspek seperti batiniyyah iaitu hal yang berkaitan dengan akidah dan keimanan, aspek 'amaliyyah yang berkaitan dengan ibadat, muamalat, munakahat serta jinayah. Di samping itu, aspek akblaqiyyah yang membincangkan tentang budi pekerti dan moral manusia sebagai individu yang bermasyarakat serta bernegara. ${ }^{10}$

\section{MAQASHID SYARIAH MEMELIHARA KEDUDUKAN AGAMA ISLAM DI MALAYSIA}

Tanah Melayu terletak di tengahtengah Asia Tenggara dan terkenal dalam kalangan pedagang sebagai 'Semenanjung Emas.' Kebanyakan ahli sejarah moden berpendapat bahawa Melaka merupakan negeri yang paling menonjol dan berperanan penting dalam penyebaran agama Islam di Tanah Melayu. Pandangan ini boleh diterima apabila dikaitkan dengan penyebaran Islam di Tanah Melayu pada abad ke-15 dan 16. Hakikatnya Islam tersebar di rantau ini lebih awal dari tarikh itu dan Melaka bukanlah negeri yang terawal menerima Islam. Ini kerana terdapat

${ }^{10}$ (Osman Bakar et.al. 2017: 48) banyak lagi negeri di Tanah Melayu sebelum Melaka yang telah menerima Islam seperti Kedah, Kelantan, Pahang dan Terengganu. Negeri-negeri ini berperanan penting dalam bidang dakwah tetapi kurang mendapat perhatian. Namun terdapat bukti-bukti sejarah yang menunjukkan bahawa peranannya sangat penting bagi menyediakan tapak awal perkembangan Islam di Tanah Melayu. ${ }^{11}$

\section{Raja atau Sultan Sebagai Ketua Agama Islam di Negeri Masing-masing.}

Raja atau Sultan bertindak sebagai ketua agama Islam di negeri masing-masing. Manakala Yang di-Pertuan Agong berperanan sebagai ketua agama di negeri baginda sendiri dan di negeri-negeri yang tidak mempunyai Raja atau Sultan iaitu di Melaka, Pulau Pinang, Wilayah Persekutuan, Sabah dan Sarawak. ${ }^{12}$

Kepimpinan raja yang baik merupakan kepimpinan yang dapat merahmati kehidupan rakyatnya sehingga pemerintahannya disanjung dan dihargai sepanjang masa. Raja sebagai pemerintah yang baik juga dapat membangunkan kerajaannya dengan kemajuan ekonomi, sosial dan pentadbiran. Ini termasuklah raja juga perlu sentiasa menjaga kepentingan agama agar dapat dijadikan panduan kehidupan dan kerajaannya. ${ }^{13}$

Dalam sejarah Kesultanan Melayu Melaka (KMM), pentadbiran negeri dilaksanakan berlandaskan kepada Hukum Kanun Melaka yang diwujudkan berpaksikan kepada syariat Islam. Kewujudan Hukum Kanun Melaka yang menjadi peraturan itu sendiri sebenarnya memperkuat kedudukan raja dari segi status quo dan penguasaan politik. Undang-undang tersebut juga secara tidak langsung dan perlembagaan tradisional mengabsahkan taraf raja berkenaan sebagai

11 (Mahayudin Haji Yahaya, 2001: 15)

12 (Mardiana Nordin \& Hasnah Hussiin, 2014:

13 (Ramlah Adam, 2016: 35) 
pemerintah (ruler) pada peringkat seluruh kerajaan. ${ }^{14}$

Raja atau Sultan dalam menjalankan tugas sebagai ketua agama Islam akan mendengar nasihat dari yang berkemahiran dalam hal ehwal agama Islam iaitu jawatan mufti. Mufti hendaklah membantu dan menasihati Duli Yang Maha Mulia Sultan berkenaan dengan semua perkara Hukum Syarak, dan dalam semua perkara sedemikian hendaklah menjadi pihak berkuasa utama di setiap negeri selepas Duli Yang Maha Mulia Sultan, kecuali jika diperuntukkan selainnya dalam Enakmen Pentadbiran Agama Islam pada setiap negeri.

Selain itu, Mufti juga menganggotai Jawatankuasa Fatwa yang ditubuhkan oleh setiap negeri. Setiap negeri mempunyai undang-undang agama Islam yang tersendiri. Contohnya, di negeri Selangor. Penubuhan Jawatankuasa Fatwa ini termaktub kepada Seksyen 46. Jawatankuasa ini terdiri daripada ahli jawatankuasa berikut yaitu; Mufti sebagai Pengerusi; Timbalan Mufti; Penasihat Undangundang Negeri; Dua orang anggota Majlis yang dinamakan oleh Majlis; Seorang pegawai dari Jabatan Agama Islam Selangor yang berkemahiran dalam hukum syarak yang dilantik oleh Majlis; Tidak kurang daripada dua orang dan tidak lebih daripada tujuk orang yang layak dan sesuai yang dilantik oleh Majlis, dan; Seorang pegawai dari Jabatan Mufti yang dilantik oleh Majlis yang berperanan sebagai Setiausaha.

Selain itu, dimaklumkan juga bahawa seseorang yang sebelum sahaja seksyen ini berkuat kuasa telah menjadi anggota Jawatankuasa Perunding Syara' yang ditubuhkan di bawah Enakmen terdahulu mestilah tertakluk kepada subseksyen (4), disifatkan telah dinamakan atau dilantik menjadi anggota Jawatankuasa Fatwa dan akan terus kekal sebagai anggota Jawatankuasa Fatwa sehingga tempoh pelantikan di bawah

14 (Muhammad Yusoff Hashim, 2015: 318)
Enakmen yang sebelum ini tamat. Jawatankuasa Fatwa boleh dan tertakluk kepada Enakmen ini bagi tujuan memutuskan segala persoalan yang timbuk berkait dengan tatacara dan amalannya. ${ }^{15}$

\section{Majlis Raja-raja.}

Ketika perundingan kemerdekaan dahulu, raja-raja telah bersetuju memberi kebenaran supaya peruntukan tentang perisytiharan agama Islam sebagai agama persekutuan dimasukkan ke dalam perlembagaan selepas diberi jaminan bahawa perisytiharan sedemikian tidak akan menjejaskan kedudukan raja-raja sebagai ketua agama di peringkat negeri masing-masing. Setelah itu apabila wujud kekosongan pada peringkat pusat atau persekutuan atas faktor tidak adanya ketua agama bagi seluruh persekutuan telah memaksa Majlis Raja-raja terpaksa berbuat sesuatu sehingga meletakkannya sebagai ketua agama persekutuan secara tidak langsung.

Agama Islam mempunyai kedudukan yang rapat dengan institusi beraja. Hal ini kerana telah diberi kebenaran kepada seseorang raja untuk meneruskan fungsi agama meskipun baginda menjalankan tugas sebagai Yang di-Pertuan Agong. Perlu dinyatakan dengan jelas bahawa Majlis Raja-raja dianggotai oleh raja-raja yang kesemuanya menjadi ketua agama. Apabila dilihat dari sudut undang-undang, ini seolah-olah mengisyaratkan proses perwakilan kuasa, sama ada kepada Majlis Raja-raja atau Yang diPertuan Agong. Ini contoh yang jelas kerana Yang di-Pertuan Agong menjalankan fungsi ketua agama persekutuan seolah-olah apabila perlembagaan mewajibkan raja-raja memberi keizinan baginda menjadi wakil mereka dalam perayaan dan amalan yang dilaksanakan pada peringkat persekutuan.

15 http://www2.esyariah.gov.my/esyariah/mal /portalv1/enakmen/State_Enact_Ori.nsf/100ae74:10 Jun 2018) 
Majlis Raja-raja berperanan dalam soal agama Islam dan wajar dilihat dalam konteks perlembagaan. Raja-raja diberi keizinan untuk terus mengekalkan kuasa budi bicara berhubungn dengan kedudukan mereka sebagai ketua agama Islam. Oleh yang demikian, persoalan berkaitan dengan agama diberikan kebenaran untuk dikendalikan oleh institusi beraja, sama ada raja-raja ataupun Majlis Raja-raja mengikut konteks dan keadaan. Ini menjelaskan bahawa Majlis Rajaraja dipertanggungjawabkan untuk menjaga martabat dan kesucian agama Islam pada peringkat persekutuan dalam usaha mengelakkan agama diambil alih oleh kerajaan persekutuan. ${ }^{16}$

Majlis Raja-raja bertindak sebagai ketua agama di negeri masing-masing. Kebiasaannya Majlis Raja-raja di setiap negeri berperanan secara bersama atau persetujuan ramai dalam menentukan hal-hal mengenai agama Islam di peringkat Persekutuan. Antara contohnya ialah penentuan tarikh mula berpuasa dan tarikh 1 Syawal. Dalam hal ini, Majlis Raja-raja akan bersama-sama memberi persetujuan. Manakala Yang di-Pertuan Agong bertindak mewakili raja-raja. Hal ini termaktub dalam Perkara 3 (2) peruntukan Perlembagaan Persekutuan Malaysia. Dalam hal-ehwal agama Islam, Yang di-Pertuan Agong di dalam sumpahnya berikrar memelihara agama ini pada setiap masa. Baginda juga adalah ketua agama Islam bagi negeri-negeri Pulau Pinang, Melaka, Sabah, Sarawak dan Wilayah Persekutuan. ${ }^{17}$

\section{Majlis Kebangsaan Hal Ehwal Agama Islam}

Majlis Kebangsaan Hal Ehwal Agama Islam ditubuhkan pada 17 Oktober 1968 oleh Majlis Raja-raja. Tujuan penubuhannya ialah untuk menyelaras pentadbiran hal ehwal

16 (Abdul Aziz Bari, 2006: 87)

17 (Ahmad Ibrahim dan Ahilemah Joned, 2007: agama Islam pada peringkat Persekutuan. Keanggotaannya terdiri daripada:

1. Seorang Pengerusi yang kebiasaannya disandang oleh Perdana Menteri.

2. Seorang wakil dari setiap negeri Semenanjung Malaysia yang dipilih dan dilantik oleh raja negeri masing-masing.

3. Wakil dari Pulau Pinang dan Melaka dilantik oleh Yang di-Pertuan Agong.

4. Wakil dari Sabah dilantik oleh Yang Dipertua Negeri Sabah.

5. Wakil dari Sarawak dilantik oleh Yang Dipertua Negeri Sarawak.

6. Lima orang ahli yang dilantik oleh Yang di-Pertuan Agong selepas mendapat persetujuan daripada Majlis Raja-raja.

Majlis Kebangsaan Hal Ehwal Agama Islam berperanan sebagai penasihat berkaitan sebarang perkara yang diajukan oleh Majlis Raja-raja, kerajaan negeri dan Majlis Agama Islam Negeri. Selain itu, Majlis Kebangsaan Hal Ehwal Agama Islam juga menasihati Majlis Raja-raja, kerajaan negeri dan Majlis Agama Islam Negeri yang berkaitan dengan hukum syarak, pendidikan Islam dan perkaraperkara lain mengenai agama Islam agar dapat diperbaik dan mengadakan penyeragaman hukum syarak serta pentadbiran Islam. ${ }^{18}$

\section{Majlis Agama Islam}

Setiap negeri mempunyai sebuah Majlis Agama Islam masing-masing. Majlis Agama Islam berperanan menasihati raja mengenai hal ehwal agama Islam. Menurut peruntukan Perkara 11 (4) Perlembagaan Persekutuan Malaysia, undang-undang negeri dan undangundang Persekutuan diberi kuasa untuk mengawal atau menyekat apa-apa aktiviti iktikad dan kepercayaan agama dalam kalangan orang Islam.

Selain itu, Perkara 12 Perlembagaan Persekutuan Malaysia memberi kuasa kepada
18 (Mardiana Nordin \& Hasnah Hussin, 2015: 
Persekutuan untuk mengadakan undangundang bagi memperuntukkan bantuan kewangan bagi penubuhan Yayasan Islam. Ini termasuk juga pembiayaan pelajaran agama Islam kepada orang Islam selain di Sabah dan Sarawak kecuali setelah mendapat kebenaran daripada Yang Dipertua Negeri. Perlembagaan Persekutuan Malaysia menjelaskan bahawa agama Islam terletak dalam Senarai Negeri. Ini bermaksud hanya negeri-negeri sahaja yang mempunyai kuasa dalam hal perundangan agama Islam. Seperti yang tertera dalam Perlembagaan Persekutuan Malaysia, terdapat beberapa perkara yang berada di bawah kuasa perundangan negeri mengenai agama Islam yaitu; Hukum syarak dan undang-undang diri serta keluarga; Adat istiadat Melayu; Wakaf; Fitrah; Zakat; Baitulmal; dan Masjid.

Contohnya bidang tugas Majlis Agama Islam Pulau Pinang. Ketua agama Islam di Pulau Pinang dipertanggungjawabkan kepada Yang di-Pertuan Agong kerana negeri ini tidak mempunyai raja atau sultan. Antara perkara penting ialah seperti berikut:

1. Maka hendaklah ada suatu badan bernama 'Majlis Agama Islam Negeri Pulau Pinang' untuk membantu dan menasihati Yang di-Pertuan Agong dalam perkara-perkara yang berhubungan dengan agama Islam.

2. Apabila seksyen ini mula berkuat kuasa, Majlis Agama Islam Negeri Pulau Pinang yang wujud sebelum permulaan kuasa kuasa itu menurut Enakmen terdahulu hendaklah disifatkan sebagai Majlis yang disebut dalam subsekyen (1).

3. Segala hak, kuasa dan kewajipan dan tanggungan yang sebelum Bahagian ini mula berkuat kuasa adalah terletak hak dan dipertanggungkan pada Majlis terdahulu hendaklah apabila Enakmen ini mula berkuat kuasa terletak hak dan dipertanggungkan pada Majlis, kecuali mana-mana yang tidak selaras dengan peruntukan-peruntukan Enakmen ini.
4. Segala jenis harta, alih dan tak alih, yang sebelum Enakmen ini mula berkuat kuasa adalah terletak hak pada Majlis terdahulu hendaklah, apabila Bahagian ini mula berkuat kuasa terletak hak pada Majlis tanpa dipindahkan, diserahkan atau dipindahmilikkan.

Keanggotaan Majlis Agama Islam adalah;

1. Seorang Yang di-Pertua;

2. Seorang Timbalan Yang di-Pertua;

3. Lima orang anggota atas nama jawatan yang hendaklah terdiri daripada orang yang pada masa itu memegang jawatan;

a. Setiausaha Kerajaan Negeri;

b. Penasihat Undang-undang Negeri;

c. Pegawai Kewangan Negeri;

d. Mufti;

e. Ketua Polis Negeri, dan

f. Tidak lebih daripada lapan anggota lain, sekurang-kurangnya lima daripada mereka hendaklah yang arif dalam hukum Syarak.

Yang di-Pertua, Timbalan Yang diPertua an anggota-anggota lain yang dilantik di bawah perenggan (1) (d) hendaklah dilantik oleh Yang di-Pertuan Agong atas nasihat Majlis Mesyuarat Kerajaan Negeri bagi apa-apa tempoh, tidak melebihi tiga tahun, sebagaimana yang ditentukan oleh Yang diPertuan Agong. Seseorang anggota yang telah tamat tempoh jawatannya boleh dilantik semula.

Jika pada bila-bila masa orang yang memegang jawatan bukan orang Islam, Yang di-Pertuan Agong hendaklah melantik seorang pegawai lain yang beragama Islam yang paling kanan selepasnya dari Jabatan atau Bahagian yang sama dengan orang itu untuk menjadi anggota bagi menggantikan tempat itu.

Tiap-tiap orang yang sebaik sebelum seksyen ini mula berkuat kuasa adalah Yang diPertua, Timbalan Yang di-Pertua atau anggota yang dilantik bagi Majlis terdahulu hendaklah, 
tertaklum kepada Enakmen ini, masing-masing terus menjadi Yang di-Pertua, Timbalan Yang di-Pertua atau anggota Majlis sehingga tempoh pelantikannya tamat. ${ }^{19}$

\section{KESIMPULAN}

Kesimpulannya, kedudukan agama Islam tetap dipelihara dengan pelaksanaan Maqasid Syariah di Malaysia. Maqasid Syariah merangkumi lima perkara iaitu agama, memelihara nyawa, memelihara akal, memelihara kehormatan dan keturunan serta menjaga harta benda. Akan tetapi yang dibincangkan dalam artikel ini hanyalah berkaitan dengan agama sahaja. Pelaksanaan Maqasid Syariah terhadap agama Islam khususnya dapat mengangkat martabat Islam sebagai agama rasmi di Persekutuan Malaysia. Di samping itu, kedudukan agama-agama lain tidak dipinggirkan. Malah juga dilindungi oleh Perlembagaan Persekutan Malaysia.

Selain itu, antara perkara yang dititikberatkan dalam agama Islam ini ialah berkaitan dengan tanggungjawab sama ada pada peringkat persekutuan atau pun negeri. Walaupun agama Islam terletak dalam bidang kuasa negeri masing-masing, akan tetapi beberapa perkara telah diselaraskan agar kedudukan agama Islam terus dipertahankan. Contohnya, setiap negeri ditubuhkan Majis Agama Islam tersendiri yang diketuai oleh Raja atau Sultan atau Yang di-Pertua negeri masingmasing. Hal sebegini penting dalam keadaan masyarakat majmuk di Malaysia yang bebas mengamalkan agama, budaya dan adat resam masing-masing.

${ }^{19}$ (http://jaipp.penang.gov.my/images/pdf/en akmen_pentadbiran_agama_islam_negeri_p_pinang_20 04.pdf, 10 Jun 2018) 


\section{DAFTAR KEPUSTAKAAN}

Alquran

Ab. Aziz Mohd Zin et.al. 2014. Tamadun Islam dan Tamadun Melayu. Kuala Lumpur: Penerbit Universiti Malaya.

Abdul Aziz Bari. 2006. Majlis Raja-Raja:Kedudukan dan Peranan Dalam Perlembagaan Malaysia. Kuala Lumpur: Dewan Bahasa dan Pustaka.

Ahmad Ibrahim dan Ahilemah Joned. 2007. Sistem Undang-Undang Di Malaysia. Kuala Lumpur: Dewan Bahasa dan Pustaka.

Ahmad Zaki Abd. Latiff, Azam Hamzah, Azhar Mad Aros. 2015. Tamadun Islam dan Tamadun Asia. Selangor: Oxford Fajar Sdn. Bhd.

http://www2.esyariah.gov.my/esyariah/mal/portalv1/enakmen/State_Enact_Ori.nsf/100ae74: 10 Jun 2018.

http://jaipp.penang.gov.my/images/pdf/enakmen_pentadbiran_agama_islam_negeri_p_pinang_ 2004.pdf

Mardiana Nordin \& Hasnah Hussiin. 20014. Pengajian Malaysia Edisi Kelima. Selangor: Oxford Fajar.

Mahayudin Haji Yahaya. 2001. Islam Di Alam Melayu. Kuala Lumpur: Dewan Bahasa dan Pustaka.

Muhammad Yusoff Hashim. 2015. Kesultanan Melayu Melaka. Kuala Lumpur:Dewan Bahasa dan Pustaka.

Osman Bakar et.al. 2017. Modul Pengajian Tamadun Islam dan Tamadun Asia. Kuala Lumpur: Penerbit Universiti Malaya.

Ramlah Adam. 2016. Pemerintahan Beraja Di Alam Melayu Merentas Zaman. Kuala Lumpur: Dewan Bahasa dan Pustaka.

Shamsul Amri Baharuddin. 2017. Modul Hubungan Etnik Edisi Kedua. Bangi: Institut Kajian Etnik.

Tun Mohd Salleh Abas (dikemaskini oleh) Haji Salleh Buang. 2006. Prinsip Perlembagaan \& Pemerintahan di Malaysia. Kuala Lumpur: Dewan Bahasa dan Pustaka. 
